while in him, his patients, rich and poor alike, mourn the loss of a distinguished ophthalmic surgeon and genial friend. During the War he served in the British Expeditionary force with the rank of Captain, R.A.M.C.(T.)

\title{
CORRESPONDENCE
}

\section{COLOURED AREAS IN THE SCLEROTIC}

\section{To the Editors of The British Journal of Ophthalmology.}

SIRS,-It happened that immediately after reading Dr. C. H. Usher's excellent article on "Coloured Areas in the Sclerotic," an example of this condition came into my consulting rooms and I considered it might be of interest to report it. It shows many points of resemblance to the cases cited by Dr. Usher, and undoubtedly belongs to this category.

History : Miss G. M., aged nine years, came to me on November 29, 1932, with complaints of some headaches and tiredness of eyes. The visual acuity, left and right, was $6 / 6$ without difficulty. Pupils reacted normally and tension was normal. On drawing aside the lids to examine the conjunctiva, I observed in the right eye a circular area of slaty-blue colour, fairly sharply delimited in all its margins, forming a collar round the limbus, not continuous, but open nasally and temporally. The proximal edge was some 2 or 3 millimetres from the limbus and it varied in depth from 4 to 8 millimetres; conjunctival vessels running over it were enlarged and movable. There were no such appearances in the left eye.

The child was the middle one of three. The irides were of a light green, those of the mother being of the same colour and the father's were reported to be blue. Both fundi were essentially normal, and the right was distinctly richer in pigment than the left. The refraction in both eyes showed a quarter of a dioptre of hypermetropic astigmatism. Hair, eyebrows and eyelashes were dark brown. The mother had never noticed the condition until I drew her attention to it, and therefore one does not know whether the condition is recent or of old standing, stationary or progressive. I shall, of course, examine her from time to time and make observations. There is no nystagmus; there is no history of consanguinity of parents.

This case tends to show, if it shows anything, that the condition can exist without any disability to the visual acuity, or the eyes generally and I fear it casts no further light on the probable aetiology.

Hoping that you will find this of sufficient interest for publication.

Yours faithfully,

D. R. GAWLER.

PERTH,

Western Australia. 